\title{
The Development of the Street-Historical Investigation of Hankow Street before 1861
}

\author{
Gang Wang¹, Qipeng Liao ${ }^{2}$ \\ ${ }^{1}$ Urban Planning Bureau of Tangshan City, Tangshan, China \\ ${ }^{2}$ Geosciences University of China, Wuhan City, China \\ Email: lucky_wg@163.com,124278022@qq.com
}

Received June $14^{\text {th }}$, 2013; revised July $15^{\text {th }}$, 2013; accepted July 30 ${ }^{\text {th }}, 2013$

Copyright (C) 2013 Gang Wang, Qipeng Liao. This is an open access article distributed under the Creative Commons Attribution License, which permits unrestricted use, distribution, and reproduction in any medium, provided the original work is properly cited.

\begin{abstract}
For a long period of time, space has only been regarded as an adjunct or background of other things. As Henri Lefebvre believes that space is not a pure physical space, but is the production of social change, social transition and social experience. It is also the production of the complex social relations together with which space together are involved in the historical process. Therefore only incorporating the street into the framework of social history, and regarding it as a part of the same process of social history, can we grasp its true essence. This paper is based on this to give an account of how Hankow street shaped and developed before 1861 and its role in historical process. This paper also reveals the role of the natural environment in the evolution of social history.
\end{abstract}

Keywords: Hankow; Local Autonomy; Benign Interaction; Community; Public Sphere

\section{Introduction}

Henri Lefebvre argues that space is neither a pure physical space nor a production of concept, but is mainly the production of society and its productive mode as well as the production of social change, social transition and social experience, the best understanding of which is the spatialisation of social order. Since space is produced by past actions, it is compatible with actions newly generated, at the same time it can contribute to certain behaviors and prohibit some other behaviors. In the complex process of society-space, space is objectively produced to affect social relationships and participate in the historical process, so Henri Lefebvre proposes to convert "production in space" to "production of space".

As a type of space, streets can never be separated from the social production and social practice and maintain an autonomous status in its morphological changes. Logic of street itself is originated from the process of city. Different economic structure, social structure, the natural environment, people's life style, and the general structure of social psychology constitute the morphological characteristics of the city's streets in a particular period, which is a dynamic process of multiple historical factors behind the characterization.

The form of Hankow streets is completely different from that of neighboring Wuchang and Hanyang (Figures 1 and 2), which break through the traditional symmetrical axis pattern. There are 4 main streets, that is, Center Street (also known as Hanzheng Street), Middle Street, Back Street and Dike Street (street on a dike), paralleled to the Han River and the Yangtze River, in which Center Street and Dike Street are much longer than the other two (Figure 1). There are many "lanes" perpendicular to the Han River and the Yangtze River so that the streets of Hankow are basically fishbone-structured. The main streets spread along from west to east with the north-south numerous lanes densely distributed, showing an unique uniform character of the city. This paper aims to incorporate process of evolution of Hankow Streets before 1861 into the framework of social history, regard it as a part of the same process of social history and try to expound how the street historically emerged and is involved in the historical process producing new social relationships, which is the trinity research method of HistorySpace-Society raised by Lefebvre.

\section{The Formation of Hankow City}

The formation of Hankow city originates from a Han River diversion in the early period of Emperor ChengHua, Ming dynasty (1465-1470). The main diversion of Han River rushes down into the Yangtze River through the northern mountain foot of Guishan Mountain (Figure 3), thus Hankow dries out of the ground leaving the three-cities (Hankow, Hanyang, Wuchang) pattern peeping clue.

Before the Han River was diverted, Hankow region is just a reed beach outside the city of Hanyang with few human beings. Located in where the Yangtze River and Han River join with flat water, Hankow forms a natural harbor in which trade merchants along the Yangtze River berth in the northern shore of Han River in order to avoid treacherous currents of the river. Neighboring rural residents had moved to Hankow gradually, then concentrated more and more population and accumulated a large number of goods. Benefiting from the diversion, the prosperity of waterway of Hankow promotes the flourishment of its commerce and spreads its name over the world.

But drying out of the ground and forming the "surrounded by water" pattern after the diversion, the early history of Hankow is doomed to suffer many a setback in its life and actually it is a 


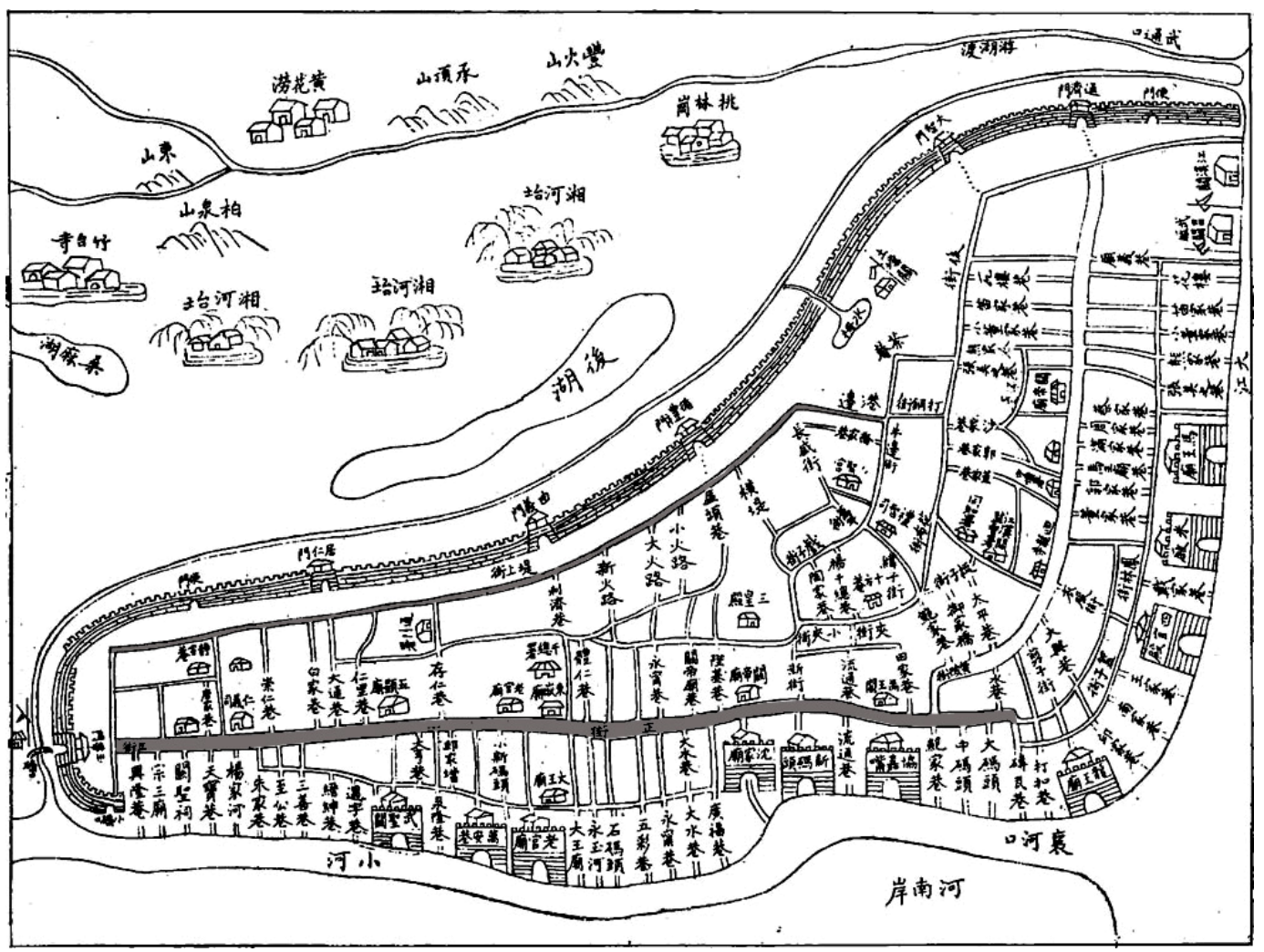

Figure 1.

The map of Hankow city in 1868, black color for Center Street and Dike Street. Source: the historical atlas of Wuhan, China Cartographic Publishing House.

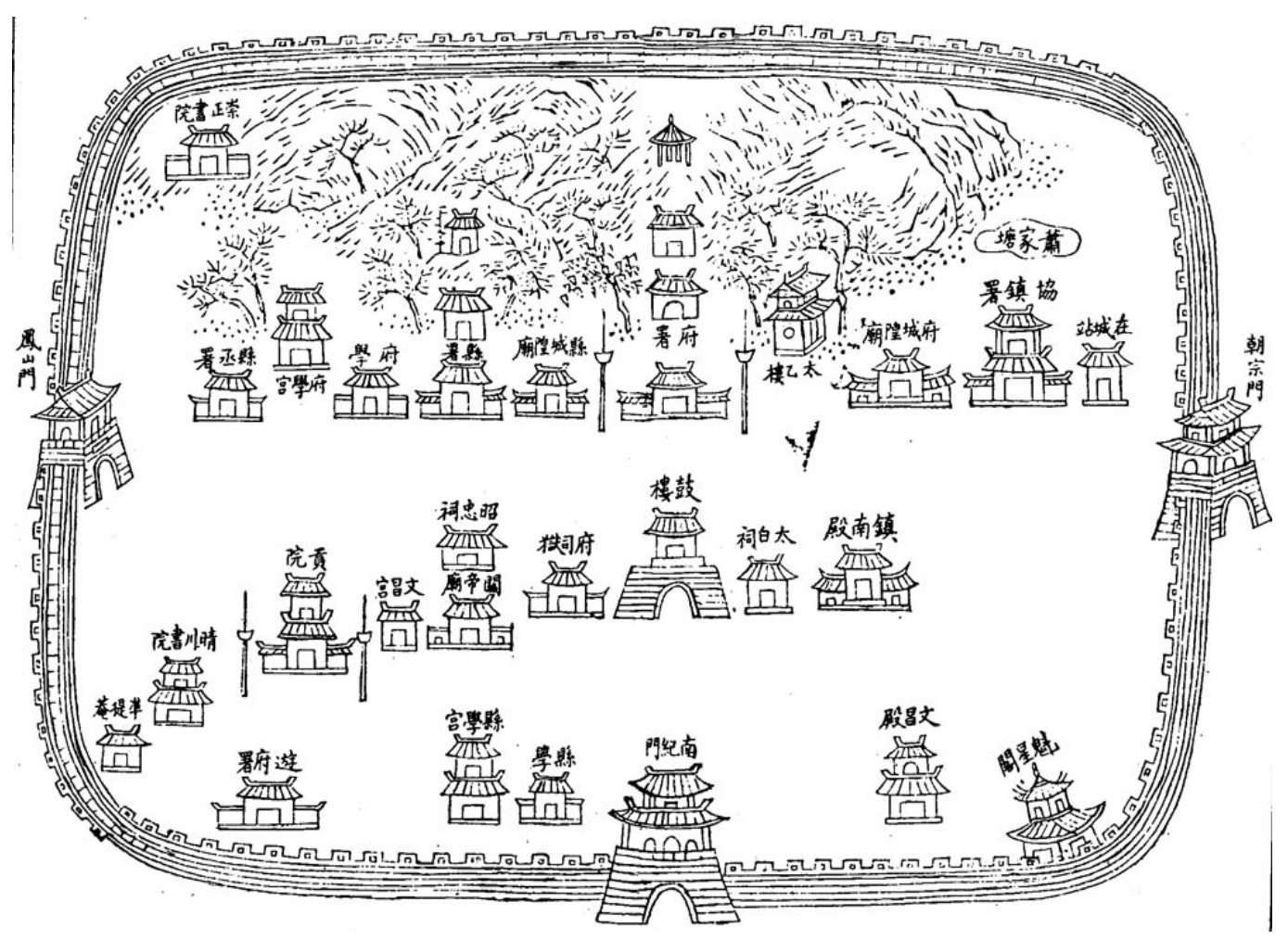

Figure 2.

The map of Hanyang city in 1868, Source: the historical atlas of Wuhan, China Cartographic Publishing House. 


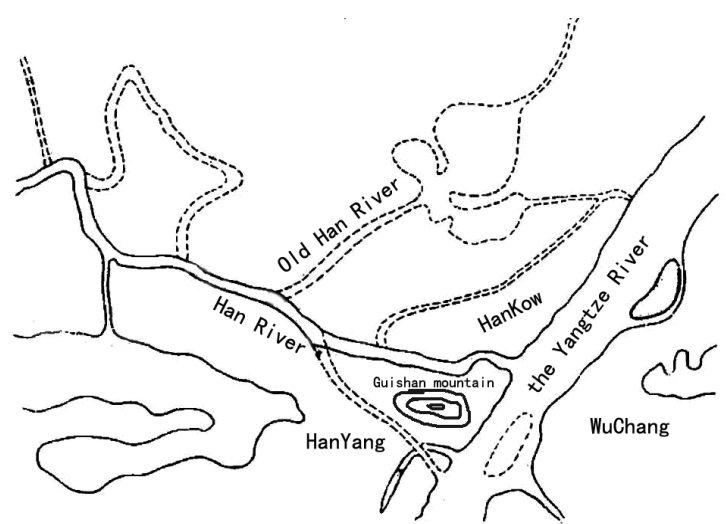

Figure 3.

The diagram of Han River diversion, where the dotted portion is the location entering the river before diversion. The pattern of Hankow surrounded by water after the diversion can be seen.

history full of struggles with floods whose influence embedded in the evolutional procedure of morphological features of its streets. There are many events in history of Hankow for the management of flooding whose traces are preserved in the streets' pattern, such as Yuan TongPan, a local official in charge of grain transportation, field, water conservancy and litigation and other matters, built a long causeway; Zhong Qianjun, as the highest local official, repaired forts; Zhang Zhidong restored bank. Waterlogging in Hankow also has a complicated relationship with the evolution of the streets which is deeply imprinted with flood fighting.

Not only that, the change of rivers and lakes is closely connected the prosperity and recession of the life of Hankow city. The alternative rise and fall and the constant changing of geographical environment of regions along rivers made areas with lighter flood first taken by class with high social status and wealth while those with serious floods are occupied by the poor who living in humble abode, which leads to spatial variation and completely different streetscapes.

Natural conditions cast a long shadow on the formation of Hankow's streets both in its physical form and social space. Of course the street can't be fully explained as a result of "natural" factors, which is probable as a consequence of superstition in "material determinism".

As Mead G. H. (George Herbert Mead, 1937) states in The Nature of Mental Processes, every object in the nature can be understood as a "collapsed action" of participating in the historical process. The street is actually the comprehensive procedure and outcome of rivers, geological movement, soil and water loss, rainfall, climate as well as the intervention of human. These factors have become an integrated one which is difficult to make a careful and detailed analysis and distinguish between each other. Therefore, such as the British anthropologist Tim Ingold (Tim Ingold, 2000) suggests that natural elements should be understood as a kind of embedded "taskscape" and embedded themselves within the generative process of the streets whose forms were always directly or indirectly influenced by them.

\section{Market and Local Society}

Driven by transportation and business, all kinds of aquatic products of Hubei province, Hunan tea, cotton, cloth and sea- sonal fresh fruit planted in Han River basin, silk and seafood of Jiangsu and Zhejiang provinces, the cattle and sheep fur from Shanxi and Shaanxi provinces, tea, oil, and four treasures of the study produced in Anhui province, Yunnan, and Guizhou's edible fungus as well as raw lacquer, tung oil, and medicinal materials of Sichuan province, China and fruit coming from Jiangxi province and Fujian province, and Guangdong and Guangxi's groceries, etc., are all transported via Hankow. The eight trading sectors of the salt, tea, grain, oil, medicinal materials, dry cargo, cotton, cowhide spread all over Hankow town due to its prosperous wharf water transportation; in the period of Emperor WanLi, Ming Dynasty, Hankow was provided as total port where merchants from provinces of Hubei, Hunan, Guangxi and Guangdong exchanged grains and paid tax and Hubei merchants sold salts. Surrounded by the economic atmosphere of "particularly favorable water conditions", Hankow gradually became the business center with gathered businessmen.

But such "crucial” place is insufficient in authority for a long time. According to the investigation of William T. Rowe in the HANKOW: Commerce and Society in a Chinese City, 17961889, "There is no temple of the City god and the drum tower in Hankow. Its position can even not compare with a small town..." To investigate its reason, the original island pattern of Hankow was supposed to be responsible for its traffic inconvenience which maintained for a long time, even after Hankow had already become a opening port leading to the dilemma of encountering that "unexpected emergency can not be informed and disposed immediately" when managing the day-to-day affairs.

Long-term relaxation of governmental management lead to Hankow's escape of harsh control of bureaucrats, which is different from Max Webber's perspective that local city is the product of the political process and local system is built and constructed by the state in China.

So, Hankow is not created as an elaborate design of the state but an outcome of continuous self organization during which the commercial activities have built households, labor sites and market and interconnected them with each other. Since Hankow's emergence benefits from water, the track of residents' daily behavior automatically has a close relationship with water which is apparently reflected in the logic of the street. The creation of Hankow streets principally depends on the rational choices of individual on the places of living which is also influenced by the natural conditions, market forces and cultural factors.

\section{Local Autonomy}

The prosperity of business in Hankow attracted a large number of foreign merchants, which accounts for about $80 \%$ to $90 \%$ of the total registered permanent residence till the 19th century while the native households of Hanyang are only about $10 \%$ to $20 \%$.

Foreign merchants sojourning in an alien land receive friendly sentiments at the first meeting like old friends from those who hold a same dialect with them, though they have never seen each other before. Thus whenever confronted with difficulties especially facing operating deficit and monetary loss, these businessmen will always first consider about the possible aids from trustworthy town fellows, even in recommending business assistants and entrusting tasks. Merchants with same registered permanent residence are close to one an- 
other; hence the natives association will spontaneously take shape and come into fashion forming hundreds of the associations in such a tiny place.

Fellow members of natives associations elect President and members to operate the management. The functions of the associations mainly contain from praying to god (usually the local idols, sages, and patron saints known by local businessmen), compatriots' celebration to protecting businessmen abroad from being bullied by local men and working together against business risk. All of the associations in Hankow build their own clubhouses.

With a large number of associations were established, the category of the relief to fellows is expanding to local public welfare including epidemic prevention, fire protection, public health, facilities construction, investments in schools charging no tuitions and assistant of education of fellows' children. The scope of maintaining the public welfare also consists of investment into charity and positive aids to the men besides fellows and counterparts as well as the weak and the poor and those who have suffered social disasters.

Suppose the associations based on blood or geopolitical relations pursuit interests to seek settlement and spiritual entrustment in an alien land, then it is obvious that the profits of the market usually accounts for the destruction of both associations. For example ROM. William records in HANKOW: Commerce and Society in a Chinese City, 1796-1889 that Jiangxi hall, Huaiqing hall and Hanzhong hall have come to a deadlock for interests in medicinal trade. Jiangxi Faction and Yellow Faction (composed by businessmen who have Jiangxi's origin and later move to the Huangzhou administration in the east of Hubei province) have finally made frictions upgrade for the fight in timber trade. To avoid this case, the guilds and clubs have built based on industry between the same occupations and set their purposes as uniting businessmen and standardizing operation, solving conflicts between counterparts and gangs and mediating disputes to make the industry develop in order.

So the clansmen associations and trade associations are built as loose social groups to provide mutual help, self-defense and negotiate with each other. ROM. William thinks that business groups achieve its own community interests by considering the interests of the other side, making out the common law of communities, establishing quality management based on the firm belief of reasonable orderly market, boycotting outside pressure from damaging themselves (including local government) and jointly undertaking the shared responsibility of the local social public utilities to realize the purpose of publicity through the unofficial coordination. In such way, business groups actually make progress to the extent of autonomous political groups, thus forming a kind of business community with autonomous nature and at the same time nation assigns rights and interests to social public domain.

\section{Symbolic Community}

In fact, temples, which are called as "symbolic community" by anthropologist Feuchtwang, play the part of maintaining community stability and sequence and serve as an important connectional link and adhesive binder.

Hankow is a world of gods that nunneries and temples can be found everywhere, such as Xinglong Nunnery, Guansheng Temple, Guanyin Temple, Tai Qing Palace, Baoshu Temple, Dawang Temple, Siguan House, Leizu Temple, Shennung Tem- ple, Huilong Temple, Mawangye Temple, Longwang Temple, Yuhuang Pavilion, Tianbao Nunnery, Yaoshi Nunnery, Tiandu Nunnery, Zhunti Nunnery, Xiguandi Temple, Jiuhua Nunnery, Wuxian Temple etc. There are more than 170 temples in varied forms.

There is a relationship between the origins of these temples and local customs, belief and legend. For example, some temples are built to pray for good weather for the crops, such as Pavilion of the Supreme Deity, Dragon King Temple and Four Gods House; some are constructed for both fear and reverence of fire, for instance, the Thunder God Temple. Guanyu temple is much more popular than the others in Hankow, the Three Kingdoms period's hero in which has turned into a commercial credit guarantee and orthodox image in commercial society for his loyalty; Others are clubs, such as Western Guanyu temple is a hall of Shanxi and Shaanxi, Shennong Temple is a medicinal materials clubhouse, Taiqing Palace is the club for jewellery shops and mill gangs, and San Huang Temple is medicinal hall, etc. The courtyards of these temples are usually where trade organization, businessman organizations, neighborhood selfhelp organizations, and scholars and poetry clubs get together to hold meetings. Not only are they symbolic but also practical, for they both bear the religious worship as well as public or half-public activities such as temple fair, election, party of guilds, holiday celebrations and some others.

Anthropologists Feuchtwang (1974), DeGlopper (1974) and Schipper (1974) regard temple worship and prayers as selfexpressions of masses on their community identity and solidity. The prayer ceremony's being put forward, namely the collective "holy" travel, strengthened the local stability sense. Although most of the labor organizations were set up on account of trade or clansman relations, common beliefs, such as bricklayers' guild and brickyard lords' guild all believe in a common god (local guardian god), which weakened the class confrontations and soften the boundaries between gangs.

Gods deeply rooted among people in Hankow are closely bound up with all sorts of groups by covering all trades and professions and providing shelter to city life and business affairs and other secular activities. People's sincere faith in gods offers the occasions and space of solution for social conflicts thus strengthens community solidarity and condenses the subculture forces. It seems that these space nodes function as the go-between is to combine and communicate among the subculture forces. The improvement of homogeneous plaques of the space has avoided the social exclusion in the process of softening of cultural tradition.

\section{Benign Interaction}

It is a false statement that Hankow is a local society completely without official power. On the one hand, the status of Hankow is increasingly becoming more and more significant therefore it is not difficult to see the official efforts made to take control of the city. In the early Qing Dynasty, Hankow city was added two independent primary-level organizations of inspection under local administration to manage city affairs respectively on the basis of original inspection department, garrisoned by different magistrates of Hanyang and actively supervised by county chief from Hanyang. Although the run-on style of management creates the situation of prevaricating responsibility between each other due to the unknown ownership, the official influence still couldn't be underestimated; On the other hand, 
the order maintenance of locality often heavily depends on the power of the official, such as real estate ownership disputes see the need to official decision. In addition that, high quality businessmen in the local place also require supports from the official force to build authority, such as merchants in Huizhou Province borrow official power to maintain their own streets clean. As a result, water porters shall not walk and exchange goods in the streets which may block traveling.

So official forces and local power have created a balance, there does not exist complete command and convey of orders between them because folk's administration often doesn't follow orders in consideration of their own interests while it also need strength and majesty of the government to coordinate some things such as the definition of property right, real estate dispute mediation, etc, so it is more a benign interaction between folk and official.

\section{Spatial Structure and Construction Activities Land Rent and Spatial Structure}

The city spatial structure is in essence the land use structure which is mainly subject to differential rents under the condition of market. Land market's demand and demand price of different land form different kinds of land rent, namely the differential rents because of distinct land positions.

Various land prices caused by different rents result in the different ways in which lands are used. Usually there is a normal curve of land prices from "peak point" down to both sides in the city, so as to form the circling structures of city land space. But not only economic factors but various factors are responsible for the differential rents including natural condition factors, market and economic reasons and social causes such as cultural system, habitus and so on.

Hankow is not simple circling structures whose land rent distribution achieves the highest rent point in shops near Center Street (also known as Hanzheng Street). It is the essence of business in the whole city that is described as an inch of land is worth a large amount of money by Zhuzhici on Hankow (Zhuzhici: occasional poems in the classical style devoted to local topics). The rent distribution of this street is not homogeneous from the most cheap housing such as shops, stores and houses at the old bank of middle Hanzheng Street "between Ji Lane and Yongning Lane" with size of "7.6 meters wide, 25.08 meters deep" "rent as 292 taels of silver a year, 24.3 taels of silver per month and 0.13 taels of silver every square meter" to the most expensive one such as "a room with shop in front and house behind between the right of Baojia Lane and left of the bank" whose area is "3.33 meters wide, 8.75 meters deep" "rent as 140 taels of silver a year on average, 11.7 taels of silver per month and more than 4.33 taels of silver every square meter a month". There are three main factors for the situation:

\section{Mixed Land Use}

Ye Diaoyuan (Mid-Qing Dynasty scholar, wrote many Zhuzhici poems on Hankow) once wrote in 1851: "every inch of land in Hankow is worth a lot”. Ten years later, missionary Josiah Cox wrote to his church in London when he went to Hankow to buy land in order to build churches that Hankow is unimaginably crowed and congested. The intensive and multiple use of land because of scarce land resources and high population density, together with local autonomy and symbolic com- munity make the social segregation and seclusion unobvious in the blocks at the same time it creates the social heterogeneous pattern in which neighborhoods have a mixed population. Under this condition, as land use originally cannot make a distinct with each other, circling structures can be difficult to be clear at a glance. ROM. William in the Hankow: Conflict and Community in a Chinese City, 1796-1895. Stanford, 1989 also pointed out that the architectural form of the shop (commercial and residential integration, a room with shop in front and house behind) restricts that there couldn't have a high degree residential and commercial distinction at the time.

\section{Began in Natural Rhythm}

According to the author's research, the highest point of Hankow originally surrounded by water is Center Street (also known as Hanzheng Street) from east of Qiaokou (name of a habitable block) to west of Jijiazui (another name of a habitable block) whose elevation is 26 meters or so. The elevation of southern River Street and northern Middle Street and Dike Street (Zhongshan road now) are all about 23 metres. The flood is quite normal for the people in Hankow which is recorded in Zhuzhici on Hankow that the sudden rise of the waters often flooded many building. As there are only a few east-west streets in Hankow such as River Street, Center Street, Middle Street, Back Street and Dike Street), the frequent waters made the streets with higher elevation a higher land value. These horizontal streets lay as ridge and purlins of a roof with Center Street as the ridge. On both sides of the east-west communicational streets, land price is higher let alone the land price in Center Street benefiting its favorable geographic position.

ROM. William reminded us of not underestimating the social importance of this spatial differentiation. In the Hankow: Conflict and Community in a Chinese City, 1796-1895, ROM William sketches for us the spatial pattern of old Hankow: Hanzheng Street was the main street and officer street where shops were mainly big business warehouses and outlets and halls; Along the River Street were cargo terminals, the highly concentrated temples and markets in a clear labor division; This Dike Street area were gathered with workers, whitesmith and mass teahouses. Either in the embankment and the Wasteland or on the beach is full of temporary shacks. In the history of the development of the city, the natural elevation of a piece of land gradually has been converted into the elevation of a class or privilege through some kind way. The land in Hankow is neither homogeneous nor be homogeneously used. Natural texture eventually will present or turn into social real estate in the use of the society.

\section{Gathering Node}

Rent and gathering effect are closely related in that the differences of gathering effect are the main sources of different rent. Those docks closely connected with production, temples intensively linked with living and markets highly bounded up with market transaction etc are naturally become people gathering places with a peak land price. Hence the land price of Hankow also shows a kind of characteristics of "Multi-spots", business area with prosperous people reaches the highest rent, such as an example taken above "a room with shop in front and house behind in Hanzheng Street between right of Baojia Lane and left of the bank" just profiting from its closeness to the Jijiazui dock and main street corner which are both business 
prosperous areas.

Although Hankow's land is not very obvious circling structures, there is still gradient hierarchical use of land which is enforced and advanced by the booming real estate market. ROM. William in HANKOW: Commerce and Society in a Chinese City, 1796-1889 expressed that the functional hierarchy of land use can be seen to some extent in Hankow. The long Hanzheng Street is not able to be called western CBD, but it is certainly the central zone. At the same time, the gathering effect of nodes causes land price sudden change, which presents the pattern of a mainline and multiple subcenters no lacking gradient hierarchical use of land. The land use pattern of Hankow shows the "process of rationalization" under the market rules, which is also characterized by natural elements and the embedded Chinese cultural system.

The significance of this kind of spatial structure lies in that construction activities in the higher rent areas are often wellorganized in a relatively orderly planning and construction way; And construction activities in the relative low rent regions, even some unexplored land without rent such as beach and the steep slope along river, are in a state of disorder and indulgence.

\section{Folk Construction Activities}

There is neither direct nor indirect materials showing official comprehensive plannings once existed in Hankow; also it has already been analyzed in the former part that government management in Hankow is frail. In addition, Hankow was originally a wasteland, so official comprehensive plannings did not exist there.

But it does not mean construction activities of Hankow are completely away from the official control because markets and streets, bridges and roads as well as city walls and so on are official duties after Hankow was brought into the management of Hanyang city. But this official control can not always be here and even if it represses the local needs, construction activities of Hankow are still produced by the local demand, in other words, local construction activities are the reflection of needs based on the production and living.

It does not mean that certain partial plans and constructions of Hankow are unorganized and disordered either. The local social autonomy has formed regionally organized constructions led by the native and trade associations meanwhile the official mainly provide public goods and necessary control, such as in the eighth year of emperor Chong Zhen's period, Ming Dynasty (1635), TongPan Yuan (an local official named Yuan mastering food shipped, field, water conservancy and litigation) presided over the repair work of the causeway and in the third years of emperor Tong Zhi's period, Qing Dynasty (1844), Zhong Qiajun presided over the building of new terminals, for instance, Wanan lane terminal.

Ziyang academy brief history gives an account of a serious of construction activities of Huizhou merchants in Hankow. This paper will describe important parts of them to make readers get a rough idea of local construction activities of Hankow.

In the thirty-forth year of Emperor KangXi's period, Qing Dynasty (1695), Huizhou merchants jointly created Ziyang Academy (also called Huizhou hall). According to records: in the thirty-third year of Emperor KangXi's period, Qing Dynasty (1694), a man surnamed Yu wanted to sell his own homestead and Huizhou men wanted to buy because of its central position. But this place was too small to use. After learning about it, all of land owners neighboring Yu expected to sell their lands at a high price at that time. So, Huizhou men purchased all the lands in a high price and expanded the area, which laid a solid foundation of building the hall. Huizhou men first reported the official after acquiring land then measured the land and recruited artisans and architects to build the academy following the inheritable ancestral temple regulations of Huizhou. After that, They purchased lands in succession from the thirty-forth year of Emperor Kang Xi’s period, Qing Dynasty (1694) to the ninth years of Jia Qing, Qing Dynasty (1804) to get more bounteous lands.

To prevent fire and convenient pedestrian, in the twelfth year of Emperor Yong Zheng's period, Qing Dynasty (1734), Huizhou men also opened up the righteous port (i.e. Xinan terminal), 9.57 meters wide, with forty-one stone stairs and Kuixing (a god blessing literati) Pavilion built on above. The Kuixing Pavillion was built to provide Huizhou fellowmen with a place where fathers and elders can admonish sons and youngers and friends can mutually exhort each other and learn from one another by exchanging views on good books and beautiful melodies and so on. The Kuixing Pavilion became an important landscape of Hankow city. Then, systematical renovation was made among the lanes and streets near the hall. Taking an example, Xinan Street, which was formerly known as Xinan lane before Zhaoqiang (a shielding wall facing the gate of a house to block outside sights and prevent loss of family wealth in FengShui theory) of the academy and was rather narrow, was opened up into an avenue in the fortieth year of Emperor Qian Long's period, Qing Dynasty (1775), more than 3.3 meters wide, 105.6 meters long. The houses on both sides of the street were property of academy whose gains belonged to the academy every year. There is another example, East Water lane, also named Taipingli, was to the east of Xinan Street. In the ninth year of Emperor Jia Qing's period, Qing Dynasty (1804), the Huizhou men bought houses to expand the lane which later was as long as Xinan Street.

In addition, Huizhou merchants also made strict regulations through the government to maintain orders of their own streets. As recorded in Imperial Instructions of New Street on the 25 February, fifth year of Emperor Jia Qing's period, Qing Dynasty (1800): as a street of Ziyang Academy, the Xinan street often became wet and unclean because of scattered and splashed water by pass-by carriers who were unwilling to take the narrow water alley often went before. The Huizhou men think, as the main street, in front of Zhaoqiang, shall be open, bright and clean. For this, they prohibited stall-selling and water drawing activities via the government in the Xinan Street and places such as Xinan dock which would be checked all the time by local officials. Shops in both sides of the street were ruled to be clean and to live no families at that time. Who had not obeyed the regulations would be made to retreat house and be replaced by new owners.

It can be seen from this example that the constructional activities of Huizhou merchants were spontaneously organized behaviors with purposes and the whole process of getting land was rather long, which reflects the strict property rights system at that time and makes constructional activities themselves a gradual adjustment process. Street building had already grasped the cultural connotations far beyond simple considerations of transportation. These constructional behaviors self-consciously complied with peripheral environments even made certain chivalrous deeds to display their own magnificence for its con- 
sidered far from business profits. The generation of the streets is immersed in the local culture, and at that time these spatial structures also promote the breeding and inheritance of the local culture.

As a result of competitions with each other in advantages, the partial constructional activities, which are led by gangs but can accommodate with surrounding environments, were quite frequent and widespread. Of course the scale and level of constructions or modifications were determined by multiple factors including financial forces, natural factors, historical conditions and so on. So although it was hard to build a comprehensive constructional model, there existed a self-organizing and orderly mode. This kind of self-organization constructions had their own goals: the first was to show the great strength of this gang itself; the second was to preserve the interests and the safety of their own gang; the third was to maintain local order.

In fact, merchants had far more impact on Hankow's space in that merchants gathered in Hankow and rooted here, which was a collision and integration process of their native cultures with local culture, obviously including form and specification of building. Businessmen's coming into Hankow provided a large amount of capital which made housing reconstruction and improvements regular activities while the strong land demand of flooded staff made housing transformation and land use refinement become inevitable. In the frequent construction and transformation processes of building, the form and specification completed a resetting process and craftsmen also gradually establish a set of regulations and procedures and formed adept and fixed techniques, so the street configuration of equal distances came from this.

So what were the forms of Hankow's buildings? Figures 4-6 are planar graphs and aerial views of club house, county department and the Confucian temple. These three types of building were the most important building types in Hankow, from which basic shapes of buildings could be roughly seen. The long and narrow layout of axisymmetric form composes of several courtyards from forward street to back street, which lie in north with southern exposure and are enclosed by bungalows and buildings.

We can boldly speculate according above that one type of architectural form in Hankow is the axial symmetry type appearing as long and narrow courtyard shape perpendicular to Han River and Yangtze River. On the one hand roads perpendicular to the river are densely distributed, which is more suitable for the shape with narrow face width; On the other hand the courtyard houses with profound origins corresponds with traditional Chinese cultures and the feudal rules which have strong applicability to make it relatively easy for businessmen from all over the country to employ.

Moreover, it was mentioned that because the most inhabitants of Hankow were merchants, there were more shop-type residential houses along the streets, some of which are houses with shops front and workshops back. These houses also appear as long and narrow layout because of the precious face width. Shop-type residential houses almost took up both sides of main streets with large streams of people, which is another major architectural type in Hankow.

Long and narrow building shape is the basic characteristics of Hankow buildings. Normalization and standardization of buildings indeed have a great impact on street forms, but it can not be arbitrarily asserted that it is the building shape which produces the fishbone-structured streets in Hankow for the
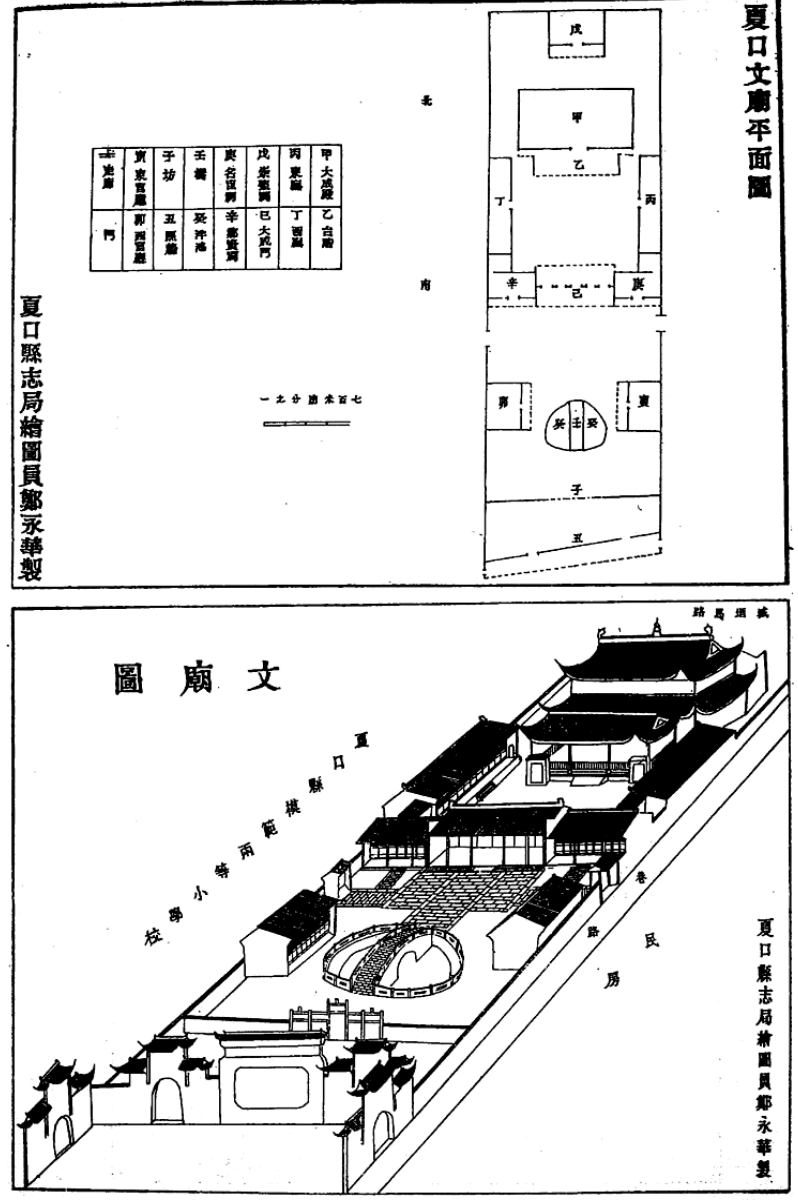

Figure 4.

The planar graph and aerial view of the Confucius temple, source from: Xia Kou County Annals.
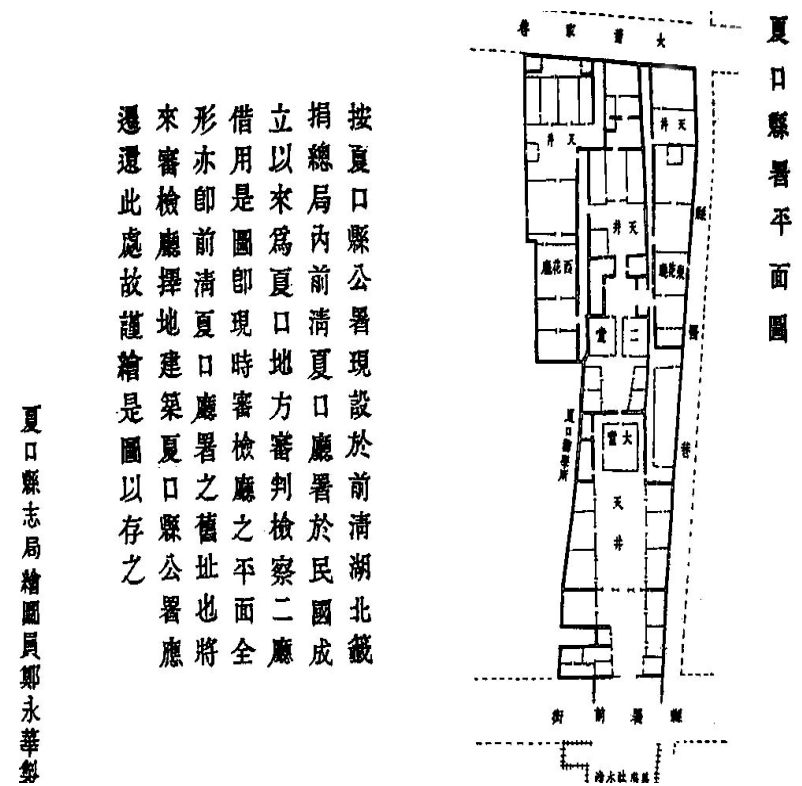

Figure 5.

The planar graph of county department, source from: Xia Kou County Annals. 


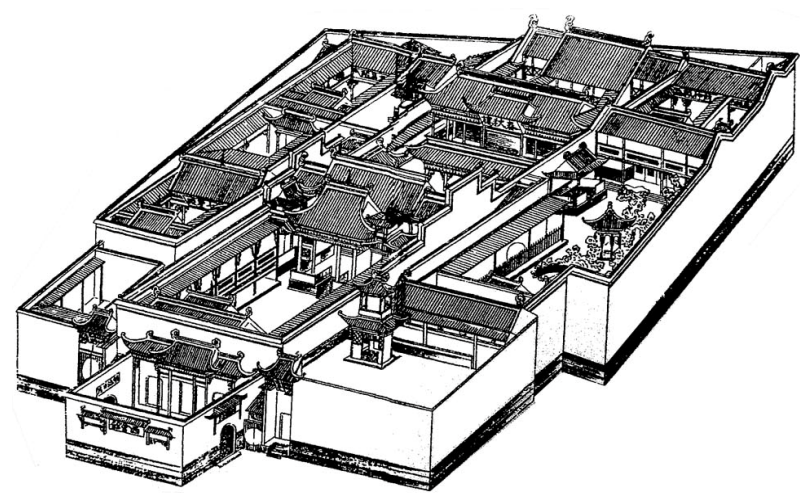

Figure 6.

The aerial view of Shaanxi club house, source from: The First One Street-Hanzheng Street of Wuhan.

relationship between the streets and buildings are like chickens to eggs, which is extremely difficult to come to a conclusion of priority. Certainly, the outcome is the result of long-term continuous adjustment of many aspects and is the optimal solution for the production and living of that time.

\section{Real Estate Transactions}

Hankow has a very active real estate market in which some real estate almost change owners in a few years and real estate business contract is an important proof in the city real estate business which is divided into official contract and civilian contrat.

The basic unit of property rights is plot, which is not usually defined by area but by the boundary (commonly known as the "the four boundaries of a piece of land" which clearly define the borders around). Property rights are at the same time supposed to get both Bao-Jia system (Bao-Jia: an old administrative system organized on the basis of households, each Jia being made up of 10 households, and each Bao of $10 \mathrm{Jia}$ ) and the neighbor's confirmation and have records in government which could be checked in case contracts for house or land lost in unexpected natural disasters. If unfortunately the whole families all died, the contracts can be passed to relatives and friends. But if relatives can be found nowhere, the friends and neighbors then have a preemptive right to buy, which largely settles disputes and maintains peace between neighbors in the streets. The contract can be very simple, and also can be rather long which should indicate the real estate details and the reason and process of trade.

There is a strictly defined property rights system in Hankow and the private property rights owners fanatically defend his land to legalize its existence, which largely maintain the stability of spatial patterns. Clear property rights benefits the stability of spatial patterns and also objectively promotes the prosperity of real estate, making the land use change dynamically. The streets are in a stable and dynamic adjustment that in favor of optimizing the using patterns of streets.

\section{The Evolution of Street}

After Han River's diversion, the ships often anchor in the north shore of Han River's upstream to avoid dangerous wind and waves of Yangtze River. The cradle of Hankow is located at the upstream of Han River, so the beginning of the streets is.
Original residents chose to live along the river where production and living are both convenient. Organizations of streets are based on building houses as a result of lacking planning.

As people increased frequently, houses became intensive. Water transportation trade took absolute priority benefiting from intersection between Han River and Yangtz River and docks were born in turn from the west to the east along the river, which determined people's living style and track. Houses organizations guided by docks and natural conditions extended along the river and developed in a linear way, so the roads also naturally winded down like shadows paralleled to the river and formed river streets. Houses chose to develop into the hinterland due to the concentrated population from terminal to River Street, and then from the River Street went as far as Main Street and Middle Street in the end. It is determined that production and living mode can not be separated with rivers, so longitudinal lanes perpendicular to rivers arose at the historic moment to facilitate further communication. The streets of Hankow were born to be characterized by the closely relation with Han River, so later even though they changed a lot but never cast away its essence. As a terminal city, it was doomed that Hankow's missions were to finish transportation, transfer and evacuation of cargoes and establish the service systems they formed. Obviously, the intensive degree of longitudinal streets was closely linked with the evacuation ability. Originating from Han Rriver, Hankow had a direct relationship with it in production and living, which was a symbiosis world of "river and body" in the water margin space.

Hankow had become a considerable scaled city till the middle period of Ming dynasty. Hanyang county set up inspection department in Hankow city and four fangs (administrative areas below the inspection department) named JuRen, YouYi, XunLi and DaZhi to manage Hankow. Bao-Jia system had long been established at that time, but Hankow streets generally changed in line with the spontaneous adjustments of market, folk selforganizations and limited official control because the official in charge was in Hanyang which was separated from Hankow by the river as well as the street pattern had already been set at that time.

Because Hankow was struck by water from both front and back and invaded by the frequent flood, in the eighth year of Emperor Chongzhen, Ming dynasty (1635), Yuan TongPan of Hanyang presided over the building of a causeway in Hankow from Qiao Mouth to the east until the Dike Mouth (now the Wangjia Lane) reaching to the shore of the Yangtze river around north part of Hankow city presenting a shape of half lunar, about more than ten $\mathrm{Li}$ (equal to 500 meters). At first it was called Yuangong Dike, the residents lived for years along the Yuangong Dike whose bank gradually turned into a road and became a causeway street. Flood struggles employed a farreaching influence on streets and these historical traces even are plain to see today. After building the dike, floods eased, city development became relatively stable, and urban expansions also became deeply trapped for a long period of time since then.

In the middle period of 17 century, all kinds of organizations begun to roll in, each gang based on hall became stronger and stronger and competed with each other fiercely which produced market segmentation. All gangs were closely guarded, thus forming the Hunan gang, Ningbo gang, Sichuan gang, Guangdong gang, Jiangxi gang, Fujian gang, Shaanxi province, Shandong gang, Huizhou gang, Henan gang and Tianjin gang etc. People in Hankow gathered based on ethnic groups and formed 
spatial patches, which was also reflected on the streets that were often turned into spatial boundaries and were usually shaped different from each in the neighbors. But people who had the common production and living styles both shared lots of nodes of frequent contacts and cultural steep of belief community, which slowly soften the heavily fortified barriers especially serious standoffs between social classes. The space plaques also approached to homogeneity and the streets displayed a unified character, too.

During the competitions among gangs, dynamic social networks with equal forces came into existence to maintain the social order operation of Hankow and kept benign interactions with the official. The balanced social network was a result of long-term accumulation and was also a process of establishing regulations during which Hankow's constructions gradually adjusted themselves, and constructional shapes and constructional behaviors were gradually standardized. Residents and craftsmen shared certain environmental knowledge out of common faith and public opinions. Although there is no express provision, these conventional rules could be obeyed freely. In other words, the similar structures of streets were the inevitable result of the practice of production and living.

Local forces took advantages of the specialization of spatial position such as halls, temples, streets to show authority and order and used the organizational way of space to ensure some purposes (power, etiquette, enlightenment) unimpeded both in the whole social body and in a smallest social and organizational part, which consolidated the social order system of Hankow. The street was generated not under a single target but in demand of multiple purposes, which is not only adopted to a variety of needs but also brought the redistribution of needs and interests.

Long confined in the narrow space with scarce land resources, the rapid development of real estate resulted in highstrength and level land use under the guidance of market mechanism. The incarceration strengthened the urban space and intensified streets. Market regulations hadn't formed the common circle structures. To search for reasons, first of all was the flood threat because natural terrain of Hankow roughly presented as a roof shape with Center Street (also called Hanzheng Street) being the highest and two sides gradually becoming low. The long-term flood hits made land price of Center Street soaring thus natural terrain transferred to social terrain and therefore there were all clubs, big shops, government offices and temples in the street. Next were the influence of cultural traditions and production and living styles: in a large number of temples, market, wharf and some other gathering centers, the land price soared so the highest land price distribution of Hankow presented an axis and scatter dots status. These key parts were usually controlled by the official or by local forces, so the patterns of the Main street, Middle street and other major streets and lanes remained unchanged through hundreds of years.

It does not mean that other narrow lanes and streets have always been prone to change. The first reason was the stability and clarity of property rights system, which made the pattern be roughly inherited. The second was the balance of folk powers, and the street morphological changes were limited in the neighborhood mutual restraint, and the result was the basic stability of the patterns.

Of course it does not rule out the case that major turningpoint events took place on the forms of narrow streets and lanes especially when emergencies happened such as floods and fires, there would be some larger local adjustments in the reconstructions. However, frequent intrusions of floods and fires and the booming real estate business objectively achieved the function of optimizing the layout of streets. This pattern was thought suitable for the social background of that time, in other words, such streets were the social production of that time.

In short, the winding changes of streets mainly led by local powers, deeply affected by natural conditions, limitedly controlled by official, rationally adapted to people's living and production, routinely adjusted during the noisy disputes between neighborhoods, profoundly steeped in cultural traditions, long regulated by feudal patriarchal. Streets had become a part of life and history and participated in the historical process instead of staying out as a single scene. At the same time the existing shape would must influence the latter, or affect the successor's choice, or habitually led the original pattern to be inherited. Although silent, streets exerted a delicate and daily influence on the life here.

Till the time of Emperor QianLong’s period and Emperor Jia Qing's period, Hankow's streets were more complex and more difficult to memory. In 1822, Fankai (He is an operating salt merchant, born in 1818, long-term residence in Hankow) gave an account in the Hankow Collected Writings that from the Ming Dynasty till now, Hankow had become a trade center where roads were so complicated that the streets can not be noted even with a map. The whole city of Hankow was like a broom lying on the ground, slightly smaller above and bigger below, in which big parts of the streets were even more complicated and difficult to remember. He roughly described the configuration of the streets: Center Street, River Street, Back Street, Middle Street and Dike Street are all main horizontal roads, which people's walking along would avoid getting lost. Center Street and Dike Street are longer than the others. These several key roads were mainly in parallel and other streets longitudinally crossed them, presenting a comb shape of spatial structure.

As William described in HANKOW: Commerce and Society in a Chinese City, 1796-1889 that Hankow is far from neat grid administrative city after planning whose natural layout is neither neat nor regular. The streets of Hankow were mainly the self-organization products out of combination of the nature and commercial trade.

The streets of Hankow were the city's most important public space and served as the autonomous social community. They were not only responsible for the transportation of the city but also were the carrier of economic behaviors and daily life. They not only met the various requirements of city living, but also promoted and cultivated social community. Hankow's quite heterogeneous streets were the carrier of collective actions, which strengthened the consciousness of the city community of the people, bred the complex social-ecological activities and created the urban spatial derivatives what we now call "pop culture" (Figure 7). Thus the relationships between people and environment and the relationships between people had reached more organic harmony and established various mutual relationships. Streets environments were providing some sort of possible behaviors and suggesting that the occurrence of certain habits.

In addition, the streets of Hankow also functioned as "public sphere" which was originally mentioned by the German Habermas in the The Structural Transformation of the Public Sphere. 


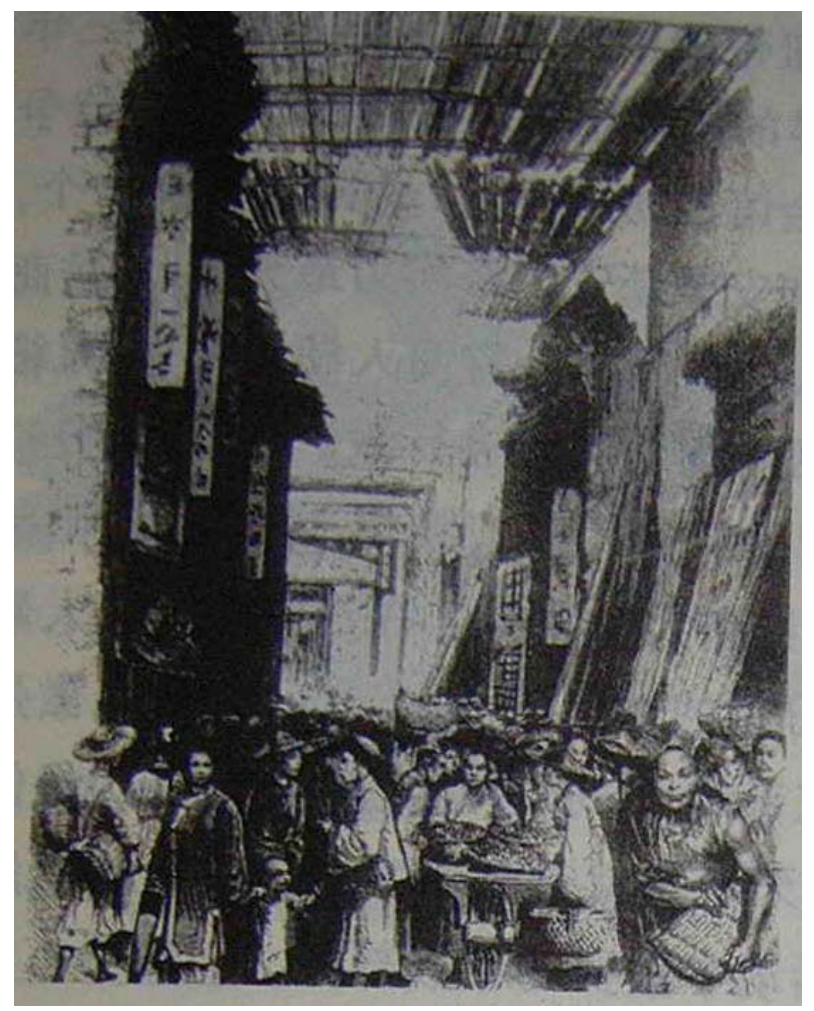

Figure 7.

A wide range of citizens in the streets of Hankow, source: In 2004, an international cultural exchange activity, Mr. YuXi found a set of 8 Hankow's etchings in the city of Arnhem, of which this is one, reflecting the prosperous scene of Center Street.

ROM. William (1984) also thought that Hankow of 19th century had already formed the land use patterns and land value distributions suitable for a capitalist city. The development of long-distance trade, the rise of larger-scale commercial firms and financial systems, the generation of organized commercial networks, the consistent advance of the local urbanization, the rapid development of the printing industry, and the rise of se- cular culture provided a social space and atmosphere conducive to the running of the public sphere.

Streets are productions of history, which no doubt participate in the process of social history. Therefore, it is not appropriate to treating them as "containers" outside social development any longer.

It should be said, the patterns of the streets are not formed in a short time as a result of multiple factors including both natural and human factors. They are not only the definition of living and production styles, but also a spatial reflection of social structure. There is an inevitable development tendency of the street's formation, but also often disturbed by unexpected factors, so it is difficult to make a detailed analysis of what causes it attributed to. Why and how streets were formed is hard to clearly distinguish, for various factors intertwining with and restricting each other. There is no absolute conclusion due to the twisted reasons and indefinite relations between causes and results.

Surely, the patterns of streets are created by history which in turn makes history. They have continued for a hundred years and in fact they have become a totally-in-one deep into the hearts of people as a kind of cultural gene and a kind of collective memory. The streets breed culture and culture influences the streets. Perhaps, there are some unspeakable internal relations among city's characters, streets' characters and even person's characters.

\section{REFERENCES}

Henri, L. (1991). The production of space. Oxford: Blackwell. Rom, W. (1984). HANKOW: Commerce and Society in a Chinese City, 1796-1889. Stanford University Press.

Rowe, W. (1989). Hankow: Conflict and Community in a Chinese City 1796-1895. Stanford University Press.

Hankow, F. K. (1999). Collected writings. Wuhan: Hubei Province People's Publishing House.

Ye, D. Y. (1985). Hankow ZhuZhiCi. Wuhan: Hubei People’s Publishing House.

Liu, F. D. (2001). The first one street-Wuhan Hanzeng Street. Beijing: People's Liberation Army Literature and Art Publishing House. 